\title{
A Virulence-Reducing Mutation in the Postharvest Citrus Pathogen Alternaria citri
}

\author{
H. Katoh, A. Isshiki, A. Masunaka, H. Yamamoto, and K. Akimitsu
}

First, second, third, fourth, and fifth authors: United Graduate School and Faculty of Agriculture, Kagawa University, Miki, Kagawa 7610795, Japan; and fifth author: PRESTO, Japan Science and Technology Agency, Kawaguchi, Saitama 332-0012, Japan. Accepted for publication 22 March 2006.

\begin{abstract}
Katoh, H., Isshiki, A., Masunaka, A., Yamamoto, H., and Akimitsu, K. 2006. A virulence-reducing mutation in postharvest citrus pathogen Alternaria citri. Phytopathology 96:934-940

Alternaria citri causes Alternaria black rot, a postharvest fruit disease, on a broad range of citrus cultivars. We previously described that an endopolygalacturonase minus mutant of $A$. citri caused significantly less

pathogenicity was performed using restriction enzyme-mediated integration. Three isolates among 1,694 transformants of A. citri had a loss in pathogenicity in a citrus peel assay, and one of these three mutants was a histidine auxotroph. Gene AcIGPD that encodes imidazole glycerol phosphate dehydratase, the sixth enzyme in the histidine biosynthetic pathway, was cloned, and the mutant containing the disrupted target gene, $A c I G P D$, caused less black rot.
\end{abstract} black rot in citrus fruit. To search for other essential factors causing symptoms in addition to endopolygalacturonase, a random mutation analysis of
Additional keywords: A. alternata, cell wall-degrading enzyme.
The effect of postharvest diseases on various crops affects both growers and consumers. The marketable yield and quality of the product is reduced, resulting in reduced returns for the grower, and purchase of poor quality produce by the consumer undermines consumer confidence and can compromise repeat sales (33). Postharvest diseases significantly reduce the quality of agricultural products, and various types of efforts such as breeding programs, appropriate production practices and handling, and sanitation during and after harvest are necessary to control the diseases (33).

One major postharvest disease of citrus is Alternaria black rot caused by Alternaria citri Ellis \& Pierce. The fungus infects either at the stylar or stem end of the fruit and causes an internal black discoloration of the fruit core during storage. We previously demonstrated the role of endopolygalacturonase (endoPG) in the virulence of $A$. citri by targeting (13). Gene disruption of the endoPG gene in $A$. citri significantly reduced the area affected by black rot on citrus fruit (13). In contrast, an endoPG mutation in the rough lemon pathotype of A. alternata, which causes Alternaria leaf spot disease and produces a host-selective ACR-toxin, was unchanged in pathogenicity on rough lemon leaves (13). These two pathogens are morphologically similar, and the pathogen causing brown spot disease was originally considered to be A. citri until its specific host range and production of host-selective toxin were identified and it was designated A. alternata (4). The endoPGs produced by $A$. citri and A. alternata rough lemon pathotype also have similar biochemical properties, and genes encoding endoPG in both fungi are $99.6 \%$ identical at the nucleotide level (13). However, the black rot symptom is not caused by A. alternata rough lemon pathotype. The results indicate that A. citri has other essential factors for causing severe black rot symptom in addition to endoPG. In addition, the pathogen can produce several nonspecific toxins such as tenuazonic acid, alternariol methyl ether, and alternariol, but these toxins have no

Corresponding author: K. Akimitsu; E-mail address: kazuya@ag.kagawa-u.ac.jp

DOI: 10.1094/PHYTO-96-0934

(c) 2006 The American Phytopathological Society known role in pathogenesis (20). Thus, a random mutation analysis of pathogenicity was performed using hygromycin-resistant transformants generated by restriction enzyme-mediated integration (REMI) (6) to further understand the factors essential to A. citri for pathogenesis.

The virulence-defective mutants selected by REMI were auxotrophs. The importance of auxotrophy at the molecular level of pathogenicity in phytopathogenic fungi has been reported during the last several years $(5,24,30,35)$. Results of these studies revealed that the importance of auxotrophy in pathogenicity is likely different for each fungal pathogen and/or their host conditions during infection and must be examined separately for each host-parasite interaction. This paper describes the features of reduced-virulence REMI mutants of $A$. citri, the isolation of A. citri gene encoding imidazole glycerol phosphate dehydratase (IGPD), and disruption of the IGPD gene to create a histidine auxotroph and the characteristics of the disruptant along with an evaluation of its pathogenicity.

\section{MATERIALS AND METHODS}

Fungal cultures and enzyme assay. Isolate ATCC 58171 of A. citri (8), isolate AC325 of A. alternata rough lemon pathotype $(3,18,19,26)$, nonpathogenic isolate $(0-94)$ of $A$. alternata $(3,15)$, and REMI and IGPD-disrupted mutants of $A$. citri were grown on V8 juice agar, pectin agar (13), or potato dextrose agar (PDA) plates, or in 200-ml Erlenmeyer flasks containing $50 \mathrm{ml}$ of potato dextrose broth (PDB) or liquid pectin medium (13). EndoPG activity of culture filtrates $(200 \mu \mathrm{l})$ was measured by a relative viscosity assay as described previously (13).

Nucleic acid manipulations. Genomic DNA and total RNA were isolated from mycelia of wild type or mutants grown at $24^{\circ} \mathrm{C}$ for 2 weeks in PDB or 25 days in liquid pectin medium as described previously $(12,13,21,22)$. Cosmid DNA was also prepared as described previously $(21,22)$.

A polymerase chain reaction (PCR) probe for Southern and northern blots was prepared with a PCR digoxigenin (DIG) Probe Synthesis Kit (Roche, Mannheim, Germany) following the manufacturer's instructions. Restriction enzyme digestion of genomic 
DNA and hybridization conditions for Southern blots were described previously $(12,13,21,22)$. For northern blots, $8 \mu \mathrm{g}$ of total RNA was loaded on each lane of agarose-formaldehyde gels and transferred to a Hybond $\mathrm{N}^{+}$membrane (Amersham Biosciences, Piscataway, NJ) by capillary transfer (27). rRNAs on the membrane were stained with $0.02 \%$ (wt/vol) methylene blue to confirm equal RNA loading (27). Hybridization was performed at $68^{\circ} \mathrm{C}$ overnight with the PCR probe $(100 \mathrm{ng} / \mathrm{ml})$. Bound probe was detected by reaction with anti-DIG antibody-alkaline phosphatase and CSPD (Roche) and exposing the membranes to X-ray film (Fujifilm RX-U, Tokyo, Japan), as described previously for both Southern and northern blots $(12,13,21,22)$.

PCR primer sets used for cloning of IGPD genes from Alternaria species and probe preparations for various blots were IGPD1 5'-ATHGAYGAYCAYCAYAC-3' (forward primer) and IGPD2 5'-GCYCTRTGRTGRTCRTT-3' (reverse primer) designed from fungal consensus sequences of IGPD: UIGPDF1 5'-AAAAGCATACATACCCCTCGG-3' (forward primer) and UIGPDR2 5'-CTATGGTAATATAACCATGCTCTGTAC-3' (reverse primer) from both $5^{\prime}$ and $3^{\prime}$ noncoding regions of AatIGPD; IGPDpF2 (forward) 5'-GCTCGAAATGTCATCAGCTATTTGTCAAGT-3' and IGPDpR4 (reverse) 5'-AGAAGTCGCTGTGCTCGTAAGG$3^{\prime}$ from the promoter region (717 bp) of $A c I G P D$; and a primer set for the endoPG (Acpg1) probe described previously (13). The reaction contained Taq DNA polymerase (2.5 units; Takara, Shiga, Japan) and was run for 2 min at $95^{\circ} \mathrm{C}$ after 30 cycles $\left(2 \mathrm{~min}\right.$ at $50^{\circ} \mathrm{C}, 1 \mathrm{~min}$ at $72^{\circ} \mathrm{C}$, and $1 \mathrm{~min}$ at $95^{\circ} \mathrm{C}$ ) with $0.5 \mu \mathrm{M}$ primer (each), $2.5 \mathrm{mM}$ dNTP mixture (each), $100 \mathrm{ng}$ of DNA as template, and reaction buffer supplied with the Taq DNA polymerase. The sequences of the PCR products were obtained from both strands by the dideoxy chain termination method (28) with the use of an ABI PRISM Dye Termination Cycle Sequencing Ready Reaction Kit (Applied Biosystems, Foster City, CA) and an automated fluorescent DNA sequencer (Model 310; Applied Biosystems). DNA sequences were aligned with CLUSTAL W (32), and homology analysis was performed via the website of the DNA Data Bank of Japan.

Fungal transformation. For REMI transformation, the HindIIIdigested vector pSH75 (17) containing the $h p h$ gene as a selection marker was used. Sixty units of restriction enzyme HindIII and $3 \mu \mathrm{g}$ of the vector pSH75 were mixed with $10^{7}$ protoplasts of A. citri, and the transformation was done with the polyethylene glycol method described previously (13).

The IGPD disruption vector was made by inserting the region containing the full-length IGPD gene amplified by the UIGPDF1 and UIGPDR2 primers into plasmid pSH75. Approximately $10^{7}$ protoplasts of $A$. citri and $3 \mu \mathrm{g}$ of the vector construct were used for transformation by the polyethylene glycol method for target gene disruption as described previously (13).

Following the transformations with both REMI and target gene disruption, the protoplasts were plated directly onto a regeneration medium containing $0.1 \%$ (wt/vol) Bacto yeast extract, $0.1 \%$ (wt/vol) Bacto casein digest, $1 \mathrm{M}$ sucrose, and $1.5 \%$ (wt/vol) Bacto agar and incubated at $24^{\circ} \mathrm{C}$ for $24 \mathrm{~h}$. The plates were then overlaid with $5 \mathrm{ml}$ of the same medium containing $100 \mu \mathrm{g}$ of hygromycin $\mathrm{B}$ per $\mathrm{ml}$ and incubated at $24^{\circ} \mathrm{C}$ for 1 day. The colonies growing on the selective medium were replated on PDA containing $50 \mu \mathrm{g}$ of hygromycin B per $\mathrm{ml}$ and purified to nuclear homogeneity by single-spore isolation. Spore germination and formation of appressorium and infection hypha of the mutants were examined on cellophane membranes with an Olympus BX60 microscope (Olympus, Tokyo, Japan) (13).

Auxotroph examination. Twelve plates of minimal medium (10) were each supplemented with different combinations of 36 possible requirements as shown in Table 1 . The final concentrations of these 36 possible requirements were $1 \mu \mathrm{g} / \mathrm{ml}$ for pyridoxin; $2 \mu \mathrm{g} / \mathrm{ml}$ for nicotinic acid; $10 \mu \mathrm{g} / \mathrm{ml}$ for biotin, folic acid, pantothenic acid, and thiamin; $15 \mu \mathrm{g} / \mathrm{ml}$ for riboflavin; $50 \mu \mathrm{g} / \mathrm{ml}$ for adenine, $p$-amino benzoic acid, choline, cytosine, guanine, hypoxanthine, inositol, thiosulphate, thymine, and uracil; and $100 \mu \mathrm{g} / \mathrm{ml}$ for alanine, arginine, aspartic acid, cysteine, glutamic acid, glycine, histidine, iso-leucine, leucine, lysine, methionine, ornithine, phenylalanine, proline, serine, threonine, tryptophan, tyrosine, and valine. Using this method, a single biochemical requirement can be identified when the fungus plated onto all 12 plates grows on two of them, one out of plates 1 to 6 and one out of plates 7 to 12 , whereas the fungus that grows on more than two plates indicates auxotrophy for multiple nutrients (10). A mycelium plug of $5 \mathrm{~mm}$ in diameter from $A$. citri REMI mutants 4-2, 6-3, or 20-4 growing on a V8 juice agar plate was placed on the center of these selection plates and incubated at $24^{\circ} \mathrm{C}$ for 5 days.

Pathogenicity assay of REMI mutants and IGPD-disrupted mutant. Citrus peel segments were presterilized by soaking in $1 \%(\mathrm{vol} / \mathrm{vol})$ sodium hypochlorite and rinsed in sterilized water several times $(13,14)$. A 5-mm-diameter mycelium plug of a V8 juice agar plate was placed on the internal surface of the presterilized peel segment $(2 \times 2 \mathrm{~cm})$ from Valencia orange (Citrus sinensis (L.) Osbeck). The peels were incubated in a sealed, sterilized plastic plate at $24^{\circ} \mathrm{C}$ for 5 days, and mycelial growth was monitored daily.

For the assay with spore inoculum, $20 \mu \mathrm{l}$ of a spore suspension containing $10^{6}$ spores per $\mathrm{ml}$ was placed under the pedicels of sterile citrus fruits, or $100 \mu \mathrm{l}$ was injected directly by the assay of Singh and Khanna (29) into the central axis of a sterilized fruit of cultivars of Washington navel orange (C. sinensis), Satsuma mandarin (C. unshiu (Mac.) Marc.), Hassaku orange (C. hassaku), and Valencia orange. The fruits were sterilized by soaking for 1 to $3 \mathrm{~h}$ in $1 \%$ ( $\mathrm{vol} / \mathrm{vol})$ sodium hypochlorite and then rinsed in sterilized water before the inoculations. The inoculated fruits were then incubated in a sealed, sterilized plastic box at $24^{\circ} \mathrm{C}$ for 3 weeks, and the fruits were sliced in half for observation of symptom development (13).

\section{RESULTS}

REMI mutation. Significant development of black rot was caused by A. citri (isolate ATCC 58171) but not by A. alternata rough lemon pathotype (isolate AC325) $(3,18,19,26)$ or A. alternata (isolate $\mathrm{O}-94)(3,15)$, when Washington navel oranges were injected with the respective inoculum (Fig. 1A). The same results were obtained for Satsuma mandarin and Hassaku and Valencia orange.

TABLE 1. Composition of selection plates to identify nutrient-deficiency mutants in Alternaria citri isolates ${ }^{\mathrm{a}}$

\begin{tabular}{|c|c|c|c|c|c|c|}
\hline \multirow[b]{2}{*}{ Plate } & \multicolumn{6}{|c|}{ Plate } \\
\hline & 1 & 2 & 3 & 4 & 5 & 6 \\
\hline 7 & Adenine & Biotin & Phenylalanine & Alanine & Arginine & Leucine \\
\hline 8 & Hypoxanthine & Folic acid & Serine & Cysteine & Ornithine & Glycine \\
\hline 10 & Guanine & Pyridoxin & Tyrosine & Thiosulphate & Proline & Histidine \\
\hline 11 & Thymine & Thiamin & $p$-Amino benzoic acid & Methionine & Glutamic acid & Lysine \\
\hline 12 & Uracil & Riboflavin & Nicotinic acid & Choline & Inositol & Valine \\
\hline
\end{tabular}

a The table was modified from the content of Holliday (10). 
Hygromycin-resistant transformants of A. citri were generated by REMI transformation with the vector pSH75 (17). Using a restriction enzyme of HindIII, a mutant library with 1,694 transformants of A. citri (isolate ATCC 58171) was constructed, and the transformants were screened for a deficiency in pathogenicity. Pathogenicity was initially tested with the citrus peel assay (13) that we developed to rapidly assess the relative pathogenicity of each transformant. Three hygromycin-resistant transformants of A. citri (4-2, 6-3, and 20-4) showed a loss of pathogenicity in the

A

ATCC58171

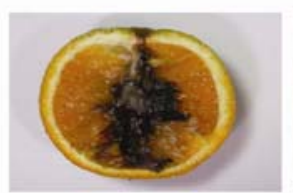

B

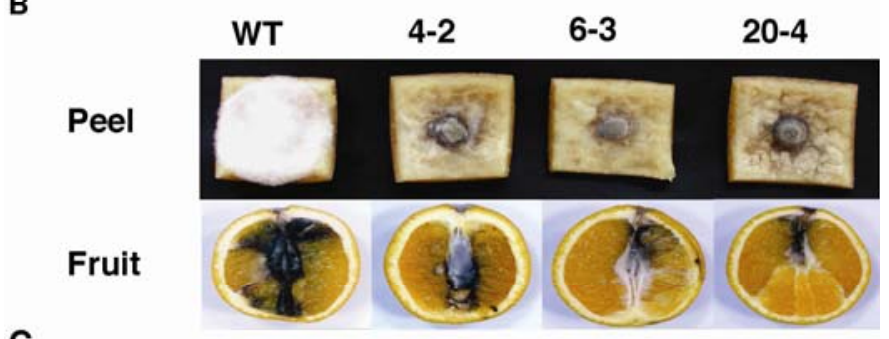

C

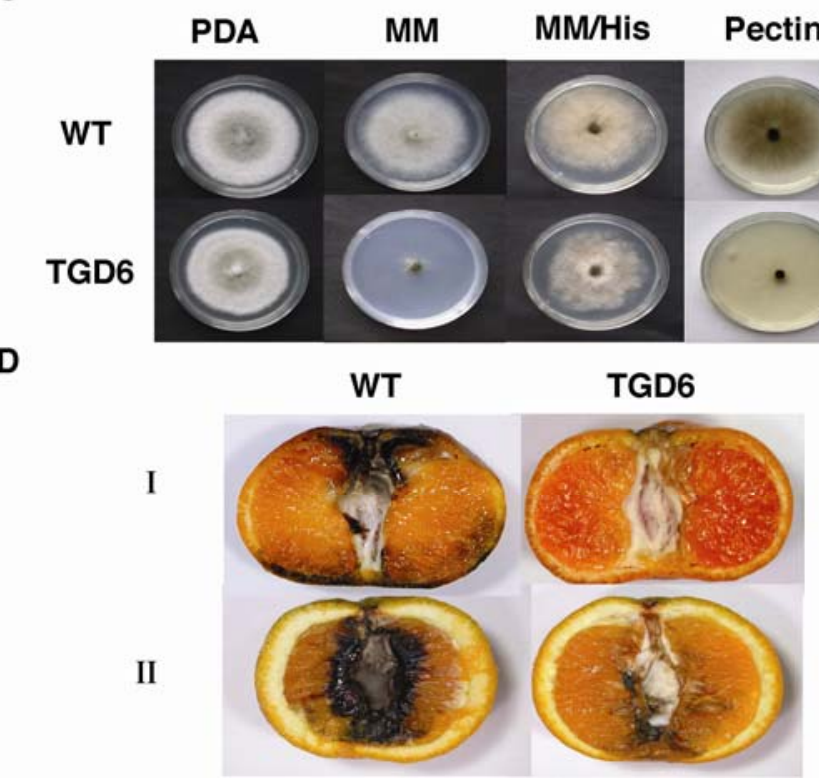

Fig. 1. Evaluation of virulence and/or fungal growth of wild types (WT) and various mutants of Alternaria citri and A. alternata. A, Spore suspension (100 $\mu \mathrm{l}$ of $10^{6}$ spores per $\mathrm{ml}$ ) of A. citri (isolate ATCC 58171), A. alternata rough lemon pathotype (AC325), or nonpathogenic A. alternata (O-94) was injected directly into the central axis of sterilized fruit of Washington navel orange and incubated for 3 weeks. B, Mycelial block of WT of A. citri (isolate ATCC 58171) or its restriction enzyme-mediated integration mutant (either 4$2,6-3$, or 20-4) was placed on the internal surface of sterilized peel segments of Valencia orange and incubated for 5 days (upper lane). A spore suspension (100 $\mu \mathrm{l}$ of $10^{6}$ spores per $\mathrm{ml}$ ) of the WT, 4-2, 6-3, or 20-4, was also injected directly into the central axis of Valencia orange fruit and incubated for 3 weeks (lower lane). C, Growth of AcIGPD disruptant TGD6 of A. citri on various media. Mycelial block of the WT of A. citri (isolate ATCC 58171) or AcIGPD disruptant TGD6 was placed on potato dextrose agar (PDA), minimal medium (MM), minimal medium plus $2 \mathrm{mg}$ of histidine per $\mathrm{ml}$ (MM/His), or pectin agar medium (Pectin), and incubated for 5 days. D, Evaluation of virulence of AcIGPD disruptant TGD6 and WT of A. citri. D-I, A spore suspension $(20 \mu \mathrm{l}$ of $10^{6}$ spores per ml) was placed under the pedicel of sterilized fruit of Satsuma mandarin and incubated for 3 weeks. D-II, A spore suspension $(100 \mu \mathrm{l}$ of $10^{6}$ spores per $\mathrm{ml}$ ) was also injected directly into the central axis of sterilized fruit of Washington navel orange and incubated for 3 weeks. citrus peel assay (Fig. 1B). Their relative virulence was also reduced compared with the wild type in a spore injection assay (Fig. 1B). Unlike the endoPG-disrupted mutant M60 (13), pSH75 was not inserted in the region of the endoPG gene in the REMI mutant genomes, and all these mutants had normal endoPG production (Fig. 2). Because these mutants had multiple insertions of vector pSH75 (data not shown), the plasmid rescue method (27) could not recover the genomic DNA region surrounding the insertion site of transforming DNA. Spore germination and appressorium and infection hypha formation of these three mutants were normal.

All these REMI mutants grew less on both pectin agar medium and minimal agar medium (Table 2), but grew well on V8 agar

A

(kb) WT 4-2 6-3 20-4 WT 4-2 6-3 20-4 M60 TGD6

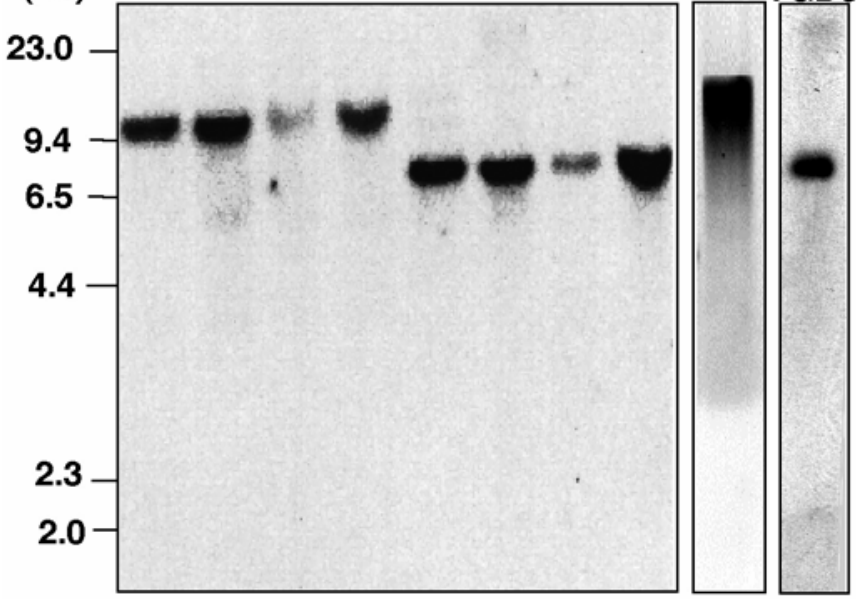

B

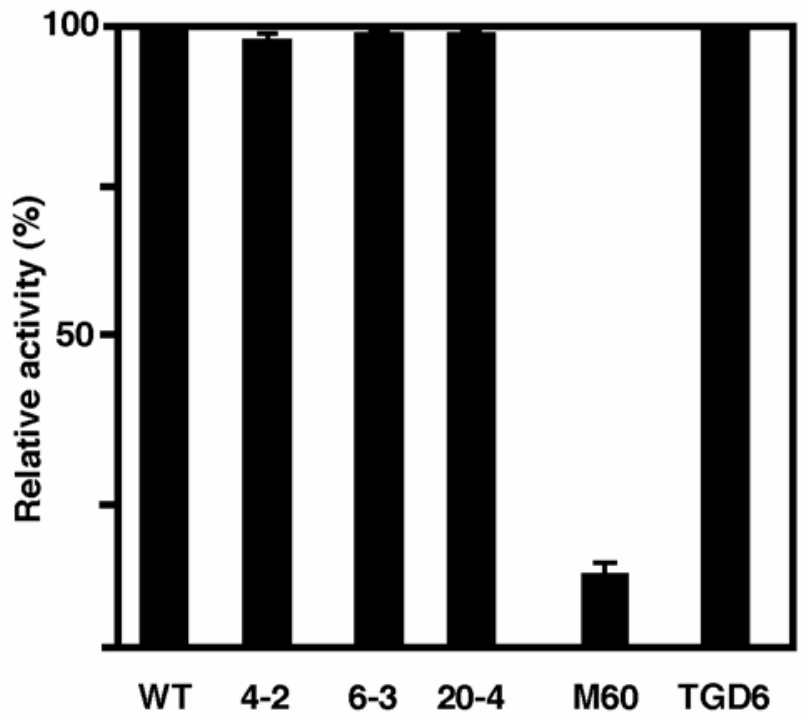

Fig. 2. Southern blot profiles using an endopolygalacturonase (endoPG) (Acpg1) probe (A) and endoPG production in culture filtrates of Alternaria citri and its mutants (B). A, Genomic DNA of A. citri wild type (WT) (isolate ATCC 58171) and restriction enzyme-mediated integration (REMI) (4-2, 6-3, and 20-4), Acpg1-disrupted (M60) (13), or AcIGPD-disrupted (TGD6) mutants was digested with the restriction enzyme HindIII or SacI and probed with A. citri endoPG gene (Acpg1) probe (13). B, EndoPG production in culture filtrates $(200 \mu \mathrm{l})$ from A. citri WT and REMI (4-2, 6-3, and 20-4), Acpg1disrupted (M60) (13), or AcIGPD-disrupted (TGD6) mutants was measured by a relative viscosity assay. Relative values (\%) for the respective activities were calculated by comparing the activity in the culture filtrate from the WT. Each data bar represents the mean of three independent replicates, and error bars represent standard deviations of the mean. 
medium (Table 2). Among these three REMI mutants, mutant 4-2 was clearly a histidine auxotroph, while others were auxotrophic for multiple nutrients (Fig. 3).

Isolation of the IGPD gene from $\boldsymbol{A}$. citri. The deduced amino acid sequences of IGPD, the sixth enzyme in the histidine biosynthesis pathway, from Aspergillus nidulans (7) (databank accession no. AF246264), Magnaporthe grisea (30) (accession no. AF027980), and Phytophthora parasitica (accession no. Z11591), were aligned, and PCR primers were designed from conserved regions of these fungal IGPD sequences (Fig. 4). PCR primers of IGPD1 5'-ATHGAYGAYCAYCAYAC-3' (forward primer) and IGPD2 5'-GCYCTRTGRTGRTCRTT-3' (reverse primer) with genomic DNA of $A$. citri as a template gave a 310-bp PCR product encoding a partial region of the IGPD gene. A cosmid genomic DNA library of A. alternata tangerine pathotype isolate SH20, which was previously constructed with partially filled Sau3AI genomic DNA fragments of SH20 in cosmid vector pMLF2 (1) at the partially filled $X h o$ I site $(1,21,22)$, was screened

TABLE 2. Growth of Alternaria citri and its restriction enzyme-mediated integration mutants on various media

\begin{tabular}{lccc}
\hline Isolates & Pectin $(\%)^{\mathrm{a}}$ & $\mathrm{MM}(\%)^{\mathrm{a}}$ & $\mathrm{V} 8(\%)^{\mathrm{a}}$ \\
\hline WT & 100 & 100 & 100 \\
$4-2$ & $36 \pm 2.1$ & $17 \pm 6.0$ & 100 \\
$6-3$ & $13 \pm 10.5$ & $10 \pm 8.2$ & 100 \\
$20-4$ & $21 \pm 10.9$ & $8 \pm 3.2$ & $80 \pm 5.0$ \\
\hline
\end{tabular}

${ }^{a}$ Relative values (\%) calculated by growth on pectin agar medium (pectin) (13), minimum agar medium (MM) (10), or V8 juice agar medium (V8) were compared with that of wild type (WT). The data are the means of three independent replicates with standard deviations of the mean.
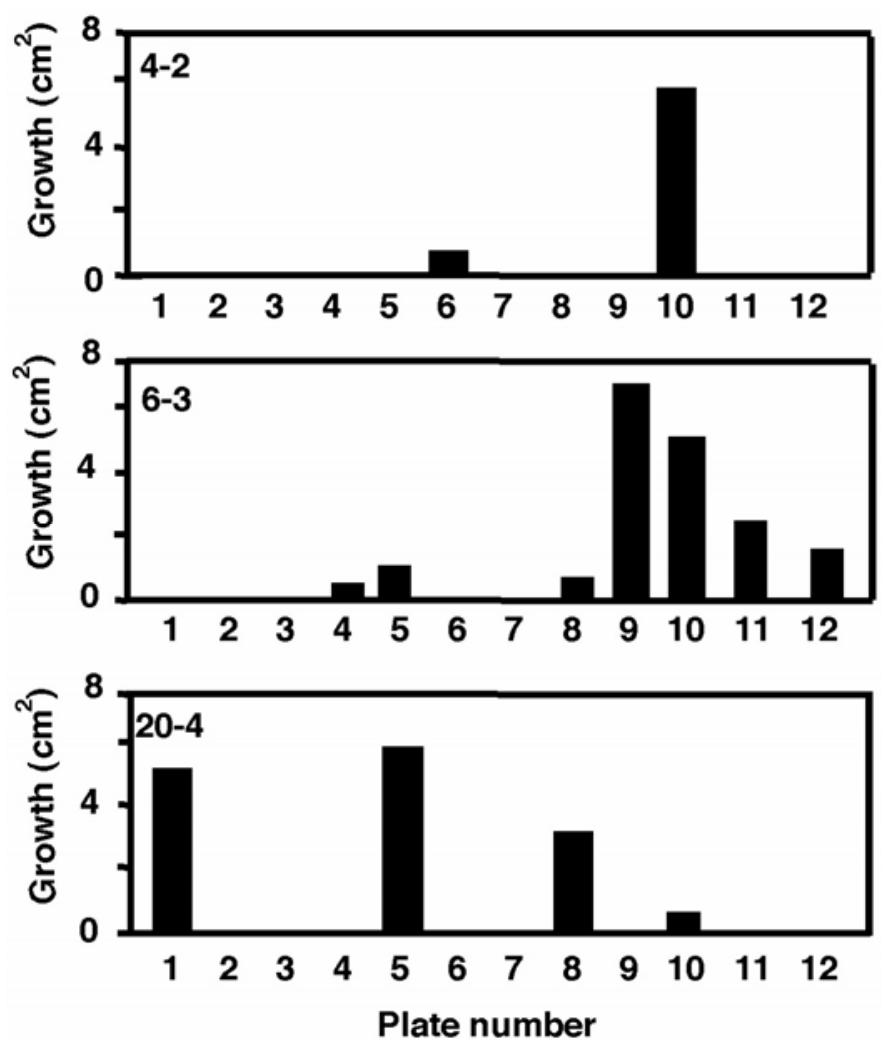

Fig. 3. Mycelial growth of restriction enzyme-mediated integration (REMI) mutants of Alternaria citri on selection plates to identify nutrient deficiencies. Twelve plates of minimal medium were each supplemented with different combinations of 36 possible requirements as shown in Table 1; plate numbers in the figure correspond to plate numbers in Table 1. A piece of mycelium plug from the REMI mutants (4-2, 6-3, or 20-4) was placed on the center of a selection plate and incubated at $24^{\circ} \mathrm{C}$ for 5 days. with a PCR-amplified, partial region of the A. citri IGPD gene probe by colony hybridization. One positive clone (CL34) was obtained. Cosmid DNA from the CL34 clone was digested with a combination of EcoRI and PstI, and the A. citri IGPD probe hybridized to an approximately $4.0-\mathrm{kb}$ fragment (data not shown). This $4.0-\mathrm{kb}$ fragment containing an entire open reading frame (ORF) region of the IGPD gene was subcloned, and the nucleotide sequence of the ORF of $705 \mathrm{bp}$ was identified and designated as AatIGPD. PCR primers of UIGPDF1 5'-AAAAGCATACATACCCCTCGG-3' (forward primer) and UIGPDR2 5'-CTATGGTAATATAACCATGCTCTGTAC-3' (reverse primer), from both the $5^{\prime}$ and $3^{\prime}$ noncoding regions of AatIGPD, gave an 809-bp PCR product using genomic DNA of $A$. citri as the template, which contained an entire ORF of the IGPD gene, with 705 bp desig-

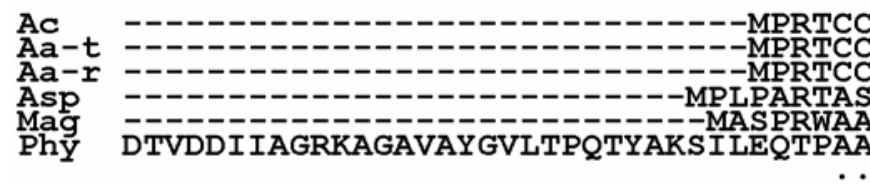

AC LNRDTNETKIOVSINLDGGDLSPYEHSDFWAAFDKE Aa-t LNRDTNETKIOVS INLDGGDLS PYEHSD FWAAFDKE Aa-r LNRDTNETKI OVS INLDGGDIS PYEHSD FWAAFDKT ASP LSRNTNETKIOVSLSLDGGVLPPYEPSSHFPVPTDP Mag LARDTNETKVKLALS IDGGDLPPDTHPSLLEAAASG Phy IGKVLEQVGASVVLTPGLGELLDLVPAVPTASKAPT

AC NLNGEGEK----------VDKDHATOKSASOEISVD Aa-t NLNGEGEK--・--・----VDKDHATOKSASOEI SVD Aa-r NLNGEGEK----------VDKDHATOK SAS Asp LEAEAAKKGI-----VPNKDAAHATOFTPTO Phy VNGKSGVREANISRVTKETSISVKLSLDGTGKSKVS

AC TGIGFLDHMIHAMAKHAGWSLRIRCKGDLHIDDHHT Aa-t TGIGFLDHMI HAMAKHAGWSLRIRCKGDLH IDDHHT $A a-r$ TGIGFLDHMI HAMAKHAGWSLRIRCKGDLH IDDHHT AsP TGIGFLDHMLHALAKHSGWSLAIRAKGDLY IDDHH Mag TGIGFLDHMLHAFAKHAGFSLLLTCOGDLHIDDHHT PhY SGIGFLDHMLTALAKHSRFD

AC SEDTFLALGTAFKNALQGSTGLARFGHAYAPLDEAL Aa-t SEDTFLALGTAFKNALOOGSTGLARFGHAYAPLDEAI Aa-r SEDTFLALGTAFKNALOGSTGLARFGHAYAPLDEAI Asp TEDTFLALGTAFTTALGAROSLARFGRGDAPLDEAL Phy ATD

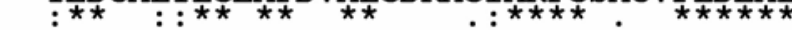

AC SRAVIDLSNRPYSI IELGLKREKIGDLSCEMIPHCI Aa-t SRAVIDLSNRPY SIIELGLKREKI GDISCEMI PHCI Aa-r SRAVIDLSNRPY SIIELGLKREKI GDLSCEMIPHCI Asp SWAVIDLSSRPWAVINIGFKREKI GDISTEMITHGI Mag SRAVVDVSNRPFAVVELGLRREKI GDISCEMI PHCI Phy SRAIVDISSRAHSEINLQLVRPSVGELS $S_{\star}$ EMITHFF

AC QSFAOASGTTLHVDCIRGDNDHHRAIESAFKALAVAI Aa-t OSFA OASGTTLHVDCIRGDNDHHRA S SAFKAIAVAI Aa-r OSFA SASGTTLHVDCIRGDNDHHRA SAFKAIAAVAI Asp OSFAOAAGVTLHIGCTYGDNDHHRA ESAFKALAVAI Mag MSFATAARLTIHVDCIRGENDHHRA SAFKALAVAV

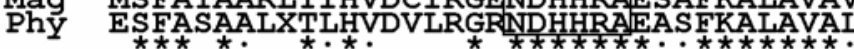

AC RHATTVVKOWEGEVRSTKGVLY-----

Aa-t RHATTVVKOWWEGEVRTKGVLY-----

Aa-r RHATTVVKOWEGEVRSTKGVLY-----

ASP RAACARRVEGEVGAGDVSGTKGPALIE

Mag RTAVGKVAGREGEVPAOGYAERLGE--

Phy $\underset{\star}{R T A V K H D A T A G V P S T K G V L A------~}$

Fig. 4. Alignment of deduced amino acid sequences of Alternaria imidazole glycerol phosphate dehydratase (IGPD) sequences and other fungal IGPD sequences. IGPD sequences are aligned by CLUSTAL W, and identical residues are indicated with asterisks. Amino acid residues that are strictly conserved among fungal IGPDs and were used as the target sites for generating polymerase chain reaction primers (IGPD1 and IGPD2) are boxed. Accession numbers for AcIGPD (Ac) for A. citri, AatIGPD (Aa-t) for A. alternata tangerine pathotype, AarIGPD (Aa-r) for A. alternata rough lemon pathotype, and IGPD genes from Aspergillus nidulans (Asp), Magnaporthe grisea (Mag), and Phytophthora parasitica (Phy) are AB246045, AB246046, AB246047, AF246264, AF027980, and Z11591, respectively. 
nated as AcIGPD. Sequence of real-time PCR product amplified with the same primer set indicated that this gene has no intron. Furthermore, the same primer set amplified an 809-bp PCR product from the rough lemon pathotype of A. alternata (the pathogen causing Alternaria leaf spot of citrus), and the entire ORF of the IGPD gene (705 bp) was also identified and designated as AarIGPD (Fig. 4). The nucleotide sequence of AcIGPD has 99.7 and $99.9 \%$ identities to AatIGPD and AarIGPD, and the deduced amino acid sequences of these genes are $100 \%$ identical (Fig. 4). CLUSTAL $\mathrm{W}$ analysis showed $65.8,62.6$, and $58.7 \%$ amino acid sequence identity with the sequences of IGPD from Aspergillus nidulans, $M$. grisea, and $P$. parasitica, respectively.

Construction of the IGPD-disrupted mutant. To evaluate the role of the histidine auxotroph in pathogenicity of A. citri, AcIGPD was disrupted by gene targeting (Fig. 5A). The 809-bp PCR product with the full length of the AcIGPD gene described earlier was subcloned into pSH75 (17) to produce the targeting vector pSH75-IGPD. Transformation of A. citri with $\mathrm{pSH75-}$ IGPD resulted in three of nine transformants with homologous recombination at the target site; all these disruptants were auxo-
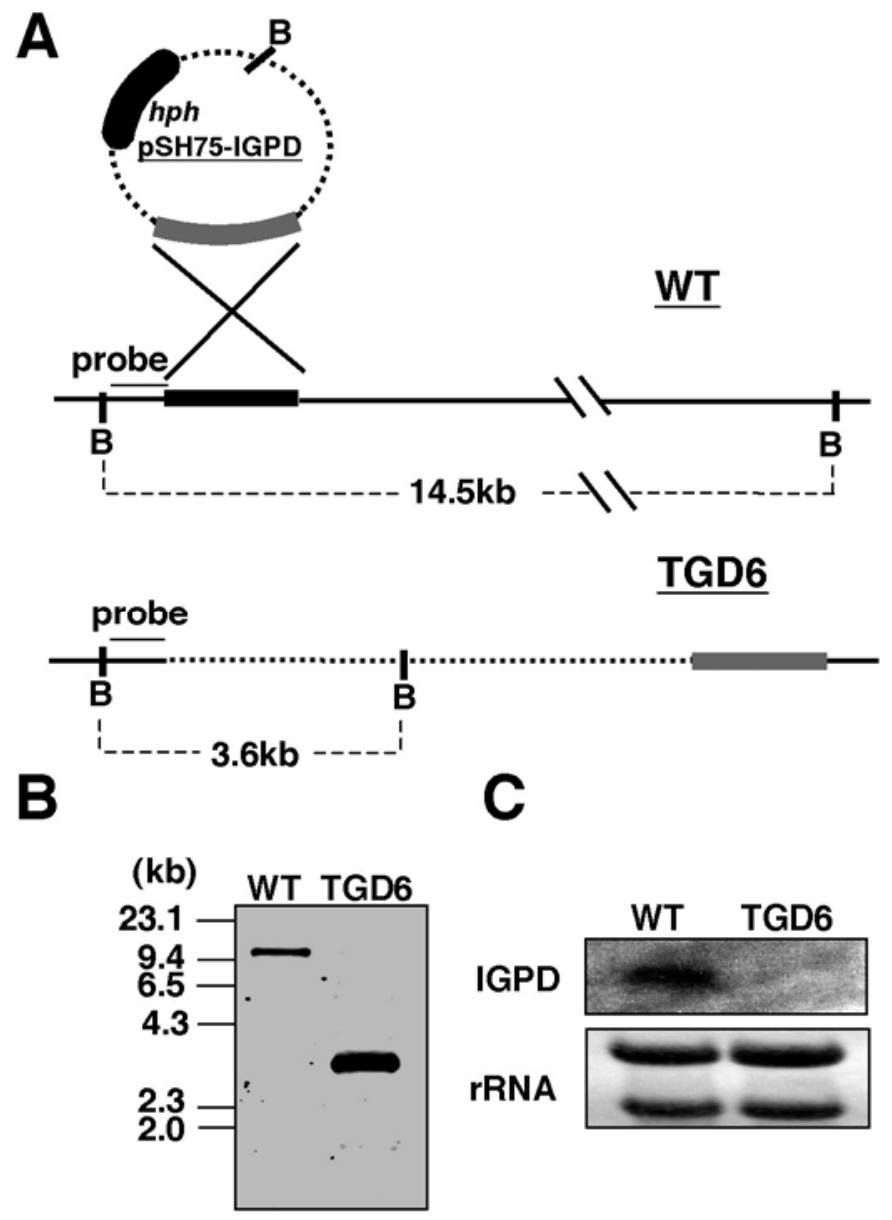

Fig. 5. Homologous recombination-mediated gene disruption of AcIGPD. A, Strategy and map for homologous recombination-mediated gene disruption of AcIGPD. B, Genomic Southern blot analysis of AcIGPD in wild type (WT: isolate ATCC 58171) of Alternaria citri and its AcIGPD disruptant TGD6. Total DNA of both was digested with the restriction enzyme BamHI and hybridized with the probe designed from the lined region (717 bp) in the map of A. C, Transcript detection of AcIGPD from wild type and AcIGPD disruptant TGD6. Total RNA from A. citri WT and its AcIGPD disruptant (TGD6) was isolated from mycelia grown on potato dextrose broth. Total RNA was electrophoresed in $1.0 \%$ agarose gels, transferred to a Hybond $\mathrm{N}^{+}$membrane, and hybridized with a polymerase chain reaction probe from region amplified by UIGPDF1 and UIGPDR2 containing an entire region of AcIGPD. Equal RNA loading in each lane was confirmed using 26S rRNA and 18S rRNA stained with methylene blue. trophs. Integration of the target vector in the transformants was analyzed by Southern blotting, and the blotting result of one (named TGD6) of these disruptants is indicated in Figure 5B. On the basis of the restriction map of AcIGPD, a probe used for the blots was expected to hybridize to $14.5 \mathrm{~kb}$ of the BamHI-digested fragment from the wild-type genome (Fig. 5B). Mutant TGD6, however, hybridized with a single $3.6-\mathrm{kb}$ band for BamHI (Fig. $5 \mathrm{~B}$ ), in which the hybridization pattern matched the predicted restriction map, assuming insertion of a single copy of pSH75IGPD at the homologous integration site (Fig. 5B). For detection of the AcIGPD transcripts, total RNA of the AcIGPD disruptant TGD6 and of the wild type was extracted from the respective mycelia grown on PDB and hybridized with the AcIGPD PCR probe. The probe hybridized to the expected size (705 bp) of transcript in total RNA from wild type but not from TGD6 (Fig. 5C).

Characterization of the IGPD-disrupted mutant. An IGPD disruptant of $A$. citri TGD6 was a histidine auxotroph (Fig. 1C). Although this mutant could not grow on minimal agar medium containing glucose as a carbon source, it did grow on minimal medium supplemented with $2 \mathrm{mg}$ of L-histidine per $\mathrm{ml}(\mathrm{MM} / \mathrm{His})$ and on PDA (Fig. 1C). TGD6 also did not grow on the plate with pectin as the single carbon source (Fig. 1C). TGD6 was not inserted in the region of endoPG gene (Fig. 2A) and had no effect on endoPG production (Fig. 2B). TGD6 had normal spore germination, appressorium, and infection hypha formation (data not shown).

IGPD-disrupted mutant and symptom development in citrus. A droplet of spore suspension of A. citri was placed under the pedicels of sterilized Satsuma mandarin fruits. After 3 weeks, the wild type caused rotting, mainly in the central axis of the inoculated fruit (Fig. 1D). Growth of TGD6, however, was restricted to the inoculation site and rotting did not develop in either the central axis or juice sac area (Fig. 1D). When spore suspensions were injected directly into the central axis of fruits of Washington navel, TGD6 grew slightly and black rot was limited to the injection site, whereas the wild-type strain developed severe rotting (Fig. 1D). The same results were also found for fruit of Valencia and Hassaku orange.

\section{DISCUSSION}

We recently demonstrated that the pathogenicity of $A$. citri depends upon production of an extracellular enzyme (endoPG) that can degrade pectic polymers in cell walls during the infection stage $(12,13)$. Various deletion analyses of the endoPG promoter using the green fluorescent protein gene as a reporter also revealed that expression of Acpgl is regulated by substrate (pectic sugars) induction and carbon catabolite repression $(2,13,14,23$, $25,34)$. EndoPG appears to be essential for the penetration of citrus peel by the black rot fungus and is essential for development of severe black rot symptoms, but disruption of the endoPG gene did not lead to a complete loss of pathogenicity (13). Further, an endoPG-disrupted mutant of the rough lemon pathotype of $A$. alternata was unchanged in pathogenicity on rough lemon leaves, and the black rot symptom is not caused by A. alternata rough lemon pathotype or nonpathogenic A. alternata. These results indicate that $A$. citri is likely to have an additional factor that is essential for pathogenesis.

Several different groups of genes playing roles in pathogenicity have been identified and isolated in phytopathogenic fungi (11) by reverse genetic approaches using random or targeted mutagenesis. In a growing number of studies on these pathogenesis genes, no universal gene has been found to control pathogenicity in any of these pathogenic fungi, and each pathosystem has been studied to determine the pathogenesis-related genes (11). We used the REMI technique for random mutation analysis to identify pathogenicity-related gene(s) other than the endoPG gene in A. citri. We selected three mutants from 1,694 REMI transformants 
for deficiency in their pathogenicity using a citrus peel assay. As noted by others, mutagenesis using this method has some limitations (30). Deletions and DNA rearrangements often occur during integration in insertional mutagenesis (30), and Alternaria species tend to integrate multiple copies of the insertion vector $(13,16$, 31). All of our selected REMI mutants showed complexity at the integration sites, and plasmid rescue to recover the integration region was impossible. REMI was successfully used to isolate a host-selective AK-toxin-defective (Tox ${ }^{-}$) mutant of A. alternata, and the genes for toxin biosynthesis were cloned from a tagged Tox $^{-}$mutant by recovery of genomic DNA flanking the tag (31). However, because other REMI mutants of A. citri in this study were fully virulent on citrus and also had this general complexity at the vector integration sites, REMI might not be an appropriate way of mutagenesis, at least for the isolate of A. citri used in this study, if simple recovery of the integration region is required.

All these REMI mutants not only had reduced virulence, but they were also auxotrophs. There is some relationship between the virulence and auxotrophy in phytopathogenic fungi. The pth3 mutant of $M$. grisea had reduced virulence as well as a partial requirement for histidine biosynthesis (30). The metl mutant of $M$. grisea also was reduced in virulence and required methionine (5). Similarly, after REMI mutagenesis of Fusarium oxysporum $\mathrm{f}$. sp. melonies, an arginine auxotrophic mutation was accompanied by reduced virulence (24). However, auxotrophic mutants are not always reduced in their virulence. For example, a histidine-deficient mutant of A. alternata apple pathotype was fully virulent on apple leaves (35). On the other hand, Arg1 and Arg2 mutants of the same pathogen via random mutation required arginine, and their reduced virulence was concomitant with a reduction in their abilities to produce AM-toxin (35).

To test the relationship between auxotrophy and pathogenicity/ virulence in $A$. citri, we cloned the gene encoding IGPD, the sixth enzyme in the histidine biosynthetic pathway. The IGPD gene is conserved among Alternaria species and exists as a single copy in the genome of $A$. citri. An IGPD disruptant of $A$. citri, TGD6, was a histidine auxotroph and reduced in its ability to cause black rot symptoms in citrus fruit, causing only a light rotting in a limited area around the inoculated site. The results indicated that IGPD is essential for the virulence of $A$. citri and that histidine is probably not obtained from the tissue of citrus fruits during infection of A. citri. This reduction in symptoms was most likely caused by a reduction in growth from the lack of histidine incurred by the defect in IGPD. According to the USDA Food Composition Data (36), the mean histidine content in navel fruit was determined as $13 \mathrm{mg}$ per $100 \mathrm{~g}$ of fruit, the third lowest of the 20 amino acids, behind $9 \mathrm{mg}$ of tryptophan and methionine and $10 \mathrm{mg}$ of cysteine. Because mycelial growth of TGD6 on agar medium is not fully restored below $2 \mathrm{mg}$ of histidine per gram of medium, the content of histidine in citrus fruit (approximately $0.13 \mathrm{mg} / \mathrm{g}$ fruit mass) is probably insufficient for complete growth recovery of the auxotroph.

As discussed earlier, several auxotrophic mutants either lost their pathogenicity or had reduced virulence $(5,24,30,35)$. In these pathosystems, the potential importance of genes that are involved in basic metabolism in the production of disease symptoms has been discussed. However, our results point to the importance of both tissue type and the physiological environment of the infection site. Thus, a defect in a particular amino acid is less important to pathogenicity and virulence if an auxotrophic mutant can obtain the missing amino acid from the plant, while the effect of auxotrophy should increase if the pathogen cannot obtain the amino acid. Idnurm and Howlett (11) reviewed this point, giving examples of the methionine auxotroph of $M$. grisea. A REMI auxotrophic mutant of $M$. grisea was selected as a nonpathogenic mutant (5), whereas others found the same mutant to be pathogenic when a different inoculation procedure was used to introduce the mutant into a different physiological environment (9).
The importance of these genes involved in basic metabolic pathways on pathogenesis is still uncertain. However, we think the genes related to auxotroph can be considered pathogenesis genes because knockout of the gene leads to a loss or reduction of virulence while full endoPG production is maintained, at least under certain infection conditions.

\section{ACKNOWLEDGMENTS}

We thank T. L. Peever, Washington State University, L. W. Timmer, University of Florida, and T. Tsuge, Nagoya University, for discussions and technical advice. This study was supported in part by grants from the Ministry of Education, Culture, Sports, Science and Technology of Japan, the Japanese Society for the Promotion of Science, and PRESTO, Japan Science and Technology Agency. Nucleotide sequences and accession numbers of the IGPD genes can be found in the DDBJ (AB246045 and AcIGPD), EMBL (AB246046 and AatIGPD), and GenBank (AB246047 and AarIGPD) databases.

\section{LITERATURE CITED}

1. Ahn, J.-H., and Walton, J. D. 1996. Chromosomal organization of TOX2, the complex locus controlling host-selective toxin biosynthesis in Cochliobolus carbonum. Plant Cell 8:887-897.

2. Akimitsu, K., Isshiki, A., Ohtani, K., Yamamoto, H., Eshel, D., and Prusky, D. 2004. Sugars and pH: A clue to the regulation of fungal cell wall-degrading enzymes in plants. Physiol. Mol. Plant Pathol. 65:271-275.

3. Akimitsu, K., Kohmoto, K., Otani, H., and Nishimura, S. 1989. Hostspecific effect of toxin from the rough lemon pathotype of Alternaria alternata on mitochondria. Plant Physiol. 89:925-931.

4. Akimitsu, K., Peever, T. L., and Timmer, L. W. 2003. Molecular, ecological and evolutionary approaches to understanding Alternaria diseases of citrus. Mol. Plant Pathol. 4:435-446.

5. Balhadere, P. V., Foster, A. J., and Talbot, N. J. 1999. Identification of pathogenicity mutants of rice blast fungus Magnaporthe grisea by insertional mutagenesis. Mol. Plant-Microbe Interact. 12:129-142.

6. Bölker, M., Bohnet, H. U., Braun, K. H., Gorl, J., and Kahmann, R. 1995. Tagging pathogenicity genes in Ustilago maydis by restriction enzyme mediated integration (REMI). Mol. Gen. Genet. 248:547-552.

7. Busch, S., Hoffman, B., Valerious, O., Starke, K., Duel, K., and Braus, G. H. 2001. Regulation of the Aspergillus nidulans hisB gene by histidine starvation. Curr. Genet. 38:314-322.

8. Cotty, P. J., and Misaghi, I. J. 1984. Zinniol production by Alternaria species. Phytopathology 74:785-788.

9. Dufresne, A., and Osbourn, A. E. 2001. Definition of tissue-specific and general requirements for plant infection. Mol. Plant-Microbe Interact. 14:300-307.

10. Holliday, R. 1956. A new method for the identification of biochemical mutants of micro-organisms. Nature 178:987.

11. Idnurm, A., and Howlett, B. J. 2001. Pathogenicity genes of phytopathogenic fungi. Mol. Plant Pathol. 2:229-240.

12. Isshiki, A., Akimitsu, K., Nishio, K., Tsukamoto, M., and Yamamoto, H. 1997. Purification and characterization of an endopolygalacturonase from the rough lemon pathotype of Alternaria alternata, the cause of citrus brown spot disease. Physiol. Mol. Plant Pathol. 51:155-167.

13. Isshiki, A., Akimitsu, K., Yamamoto, M., and Yamamoto, H. 2001. Endopolygalacturonase is essential for citrus black rot caused by Alternaria citri but not for brown spot caused by Alternaria alternata. Mol. PlantMicrobe Interact. 14:749-757.

14. Isshiki, A., Ohtani, K., Kyo, M., Yamamoto, H., and Akimitsu, K. 2003. Green fluorescent detection of fungal colonization and endopolygalacturonase gene expression in the interaction of Alternaria citri with citrus. Phytopathology 93:768-773.

15. Ito, K., Tanaka, T., Hatta, R., Yamamoto, M., Akimitsu, K., and Tsuge, T. 2004. Dissection of the host range of the fungal plant pathogen Alternaria alternata by modification of secondary metabolism. Mol. Microbiol. 52:399-411.

16. Johnson, R. D., Johnson, L., Itoh, Y., Kodama, M., Otani, H., and Kohmoto, K. 2000. Cloning and characterization of a cyclic peptide synthetase gene from Alternaria alternata apple pathotype whose product is involved in AM-toxin synthesis and pathogenicity. Mol. Plant-Microbe Interact. 13:742-753.

17. Kimura, N., and Tsuge, T. 1993. Gene cluster involved in melanin biosynthesis of the filamentous fungus Alternaria alternata. J. Bacteriol. 175:4427-4435.

18. Kohmoto, K., Akimitsu, K., and Otani, H. 1991. Correlation of resistance and susceptibility of citrus to Alternaria alternata with sensitivity to host- 
specific toxins. Phytopathology 81:719-722

19. Kohmoto, K., Scheffer, R. P., and Whiteside, J. O. 1979. Host-selective toxins from Alternaria citri. Phytopathology 69:667-671.

20. Logrieco, A., Visconti, A., and Bottalico, A. 1990. Mandarin fruit rot caused by Alternaria alternata and associated mycotoxins. Plant Dis. 74:415-417.

21. Masunaka, A., Ohtani, K., Peever, T. L., Timmer, L. W., Tsuge, T., Yamamoto, M., Yamamoto, H., and Akimitsu, K. 2005. An isolate of Alternaria alternata that is pathogenic to both tangerines and rough lemon and produces two host-selective toxins, ACT- and ACR-toxins. Phytopathology 95:241-247.

22. Masunaka, A., Tanaka, A., Tsuge, T., Peever, T. L., Timmer, L. W., Yamamoto, M., Yamamoto, H., and Akimitsu, K. 2000. Distribution and characterization of $A K T$ homologs in the tangerine pathotype of Alternaria alternata. Phytopathology 90:762-768.

23. McCready, R. M., Walter, E. D., and Maclay, W. D. 1950. Sugars of citrus juices. Food Technol. 4:19-20.

24. Namiki, F., Matsunaga, M., Okuda, M., Inoue, I., Nishi, K., Fujita, Y., and Tsuge, T. 2001. Mutation of an arginine biosynthesis gene causes reduced pathogenicity in Fusarium oxysporum f. sp. melonis. Mol. Plant-Microbe Interact. 4:580-584.

25. Ohtani, K., Isshiki, A., Katoh, H., Yamamoto, H., and Akimitsu, K. 2003. Involvement of carbon catabolite repression on regulation of endopolygalacturonase gene expression in citrus fruit. J. Gen. Plant Pathol. 69:120125.

26. Ohtani, K., Yamamoto, H., and Akimitsu, K. 2002. Sensitivity to Alternaria alternata toxin in citrus because of altered mitochondrial RNA processing. Proc. Natl. Acad. Sci. USA 99:2439-2444.

27. Sambrook, J., Fritsch, E. F., and Maniatis, T. 1989. Molecular Cloning: A
Laboratory Manual. 2nd ed. Cold Spring Harbor Laboratory, Cold Spring Harbor, NY.

28. Sanger, F., Nickien, S., and Coulson, A. R. 1997. DNA sequencing with chain-terminating inhibitors. Proc. Natl. Acad. Sci. USA 74:5463-5467.

29. Singh, R. S., and Khanna, R. N. 1966. Black rot of mandarin orange caused by Alternaria tenuis Auct. Plant Dis. Rep. 50:127-131.

30. Sweigard, J. A., Carroll, A. M., Farrall, L., Chumley, F. G., and Valent, B. 1998. Magnaporthe grisea pathogenicity genes obtained through insertional mutagenesis. Mol. Plant-Microbe Interact. 11:404-412.

31. Tanaka, A., and Tsuge, T. 2000. Structural and functional complexity of the genomic region controlling AK-toxin biosynthesis and pathogenicity in the Japanese pear pathotype of Alternaria alternata. Mol. PlantMicrobe Interact. 13:975-986.

32. Thompson, J. D., Higgins, D. G., and Gibson, T. J. 1994. CLUSTAL W: Improving the sensitivity of progressive multiple sequence alignment through sequence weighting, position-specific gap penalties and weight matrix choice. Nucleic Acids Res. 22:4673-4680.

33. Timmer, L. W., and Duncan, L. W. 1999. Citrus Health Management. The American Phytopathological Society, St. Paul, MN.

34. Ting, S. V., and Attaway, J. A. 1971. Citrus fruit. Pages 107-169 in: The Biochemistry of Fruits and Their Products, Vol. 2. A. C. Hulme, ed. Academic Press, London.

35. Tsuge, T., Hayashi, N., and Nishimura, S. 1987. Selection of auxotrophic mutants and heterokaryosis in Alternaria alternata. Ann. Phytopathol. Soc. Jpn. 53:182-190.

36. U.S. Department of Agriculture-Agricultural Research Service. 2005. USDA Nutrient Database for Standard Reference, Release 18. Nutrient Data Laboratory Home Page. Published online. http://www.ars.usda.gov/ $\mathrm{ba} / \mathrm{bhnrc/ndl.}$ 